\section{Age and Risk of Post-Halothane Jaundice}

The crude distribution by age of our surgical patients is the same as those reported to the C.S.D.-for example, for those aged $60+$ years, S. Wales $=43.6 \%$ and C.S.D. $=43.5 \%$. Age does not seem to increase the risk. However, our survey shows (Table V) that the older age group is more likely than the others to have had two anaesthetics within four weeks.

\section{Conclusions}

There is a significant association between the occurrence of post-halothane jaundice and a previous administration of halothane when the interval between the two halothane anaesthetics is four weeks or less.

The risk is in any case small and seems to lie between 1 case in 6,000 (Cardiff data) and 1 case in 22,000 (average of C.S.D. data) repeat halothane anaesthetics within four weeks. In the case of patients who had not had halothane within the previous four weeks the risk is smaller still. From the C.S.D. data it appears to be less than 1 in 600,000 . On the assumption that the average consultant anaesthetist administers 1,000 anaesthetics per annum and that if all the patients having second anaesthetics within four weeks were given halothane, in a working life of 30 years he will have administered such repeat halothane anaesthetics to about 2,000 patients. Most therefore of the consultant anaesthetists in the British Isles are likely to complete their professional lives without seeing a single case of halothane jaundice.
There seems therefore little reason, on present evidence, to stop halothane anaesthesia. Nevertheless, and in spite of the rarity of jaundice, it is reasonable to avoid halothane when it has been administered to the same patient during the previous four weeks. However, this advice assumes that there is an equally effective and safe alternative with which the anaesthetist is familiar. Otherwise it might mean that by avoiding a rare cause of morbidity or mortality a more common one is introduced.

We wish to acknowledge the help and co-operation we received from the Committee on Safety of Drugs, who not only supplied data but also gathered additional information where necessary. We also thank Professor D. Finney, F.R.S., for advice, the University Hospital of Wales (H.M.C.) and the Glantawe H.M.C. for kindly granting us permission for the surveys, and our medical and nursing colleagues for their good will. Finally, we thank the Imperial Chemical Industries Ltd. (Pharmaceutical Division) for a grant to aid this research.

\section{References}

General Register Office (1958-68). Registrar General's Statistical Review of England and Wales, for the years 1957 to 1967, Part 1, Tables Medical.

Ministry of Health (1958-68). Annual Reports, for the years 1957 to 1967, London, H.M.S.O.

Mushin, W. W., Rosen, M., Bowen, D. J., and Campbell, H. (1964). British Medical fournal, 2, 329.

Mushin, W. W., Campbell, H., and Ng, W. S. (1967). British fournal of Anaesthesia, 39, 323.

National Halothane Study (1969). Report to the Committee on Anaesthesia, Division of Medical Sciences, National Academy of Sciences, Washington, D.C.

\title{
Measurement of Blood Losses before and after Renal Transplantation
}

\author{
KEITH BODDY, A. L. LINTON, D. H. LAWSON, GEORGE WILL
}

British Medical fournal, 1971, 3, 22-24

\section{Introduction}

The use of whole-body radioactivity monitors has facilitated the measurement of blood losses (Price et al., 1962, 1964; Holt et al., 1967; Will et al., 1970a). Using this technique, we have studied blood losses in a group of patients with severe chronic renal failure.

The management of the disease was considered in three stages; the predialysis period, the period of regular dialysis therapy, and the stage following nephrectomy and successful renal homograft. It was possible to study blood losses in the

Scottish (Universities) Research Reactor Centre, East Kilbride, Glasgow

KEITH BODDY, PH.D., F.INST.P., Senior Lecturer (Health Physics and Nuclear Medicine)

Western Infirmary, Glasgow

A. L. LINTON, F.R.C.P.ED., F.R.C.P.GLAS., Consultant in Renal Diseases (Present address: Renal Unit, Victoria Hospital, London, Ontario, Canada)

D. H. LAWSON, M.B., M.R.C.P.ED., Senior Registrar, Renal Unit (Present address: Department of Clinical Pharmacology, Tufts University, School of Medicine, Waltham, Mass)

Gateside Hospital, Greenock

G. WILL, F.R.C.P.GLASG., M.R.C.P.ED., Consultant Physician same patient during different stages in the management of the disease.

\section{Patients and Methods}

The MERLIN mobile whole-body radioactivity monitor (Boddy, 1967) of the Scottish Universities Research Reactor Certre was used. The monitor has a shadow shield of 7 tons $(7,112 \mathrm{~kg})$ of lead with a sodium detector, $29 \cdot 2 \mathrm{~cm}$ diameter by $10.2 \mathrm{~cm}$ depth, in a central turret. Lying on a motorized couch, the subject passes beneath the detector in the supine and then in the prone position. Output pulses from the detector are taken to a T.M.C. 400-channel pulse-height analyser.

The study was carried out on six men. Each had been given from 0.5 to $1 \mu \mathrm{Ci}$ of ${ }^{59} \mathrm{Fe}$ intravenously some weeks earlier and red cell incorporation of ${ }^{59} \mathrm{Fe}$ was measured at 14 days after administration. Daily body ${ }^{59} \mathrm{Fe}$ loss was measured in all patients by the techniques we have previously described (Will and Boddy, 1967). All patients were suffering from severe chronic renal failure secondary to chronic glomerulonephritis, chronic pyelonephritis, or polycystic disease of the kidneys. All had creatinine clearances of $4 \mathrm{ml}$ per minute or less. At some stage all had received regular dialysis therapy with a Kolff twin-coil artificial kidney. During the course of the study both Chron-a-coils and Ultra-flo-100 coils (BaxterTravenol) were used. Dialysis was performed either twice or thrice weekly as noted. Each dialysis was of 10 hours' duration. 


\section{Case 1}

When the study was started this patient, a 25-year-old man, had already been undergoing regular dialysis therapy for nine months. The 14-day red cell incorporation of ${ }^{59} \mathrm{Fe}$ was $17 \%$ and the mean daily whole-body ${ }^{59} \mathrm{Fe}$ loss measured over a period of 37 days was $0.54 \%$.

During the first $\mathbf{1 4}$ days of the study he was dialysed five times. The total body blood loss during this period was estimated to be $650 \mathrm{ml}$, an average loss of $130 \mathrm{ml}$ of whole blood per dialysis. $\mathrm{He}$ then had a leg shunt installed and during the next three weeks dialysis was required thrice weekly. A Cimino-Brescia arteriovenous fistula was then inserted and the number of dialyses reduced to twice a week. In the interval between the whole-body counts on days 43 and 57 the leg shunt had been removed because of bleeding. During this 14 -day period the body ${ }^{59} \mathrm{Fe}$ loss was $7 \%$, representing a whole blood loss of $850 \mathrm{ml}$. Dialysis was continued twice weekly. During the period between days 69 and 96 the patient had greater losses of blood in the dialysis coils because of clotting associated with poor flow from the new fistula. These results are shown in Fig. 1. Curve A shows the pattern of blood loss during this period. The steeper parts of the curve indicate increased rates of blood loss coinciding with either increased frequency of dialysis or episodes of bleeding from shunt or fistula.

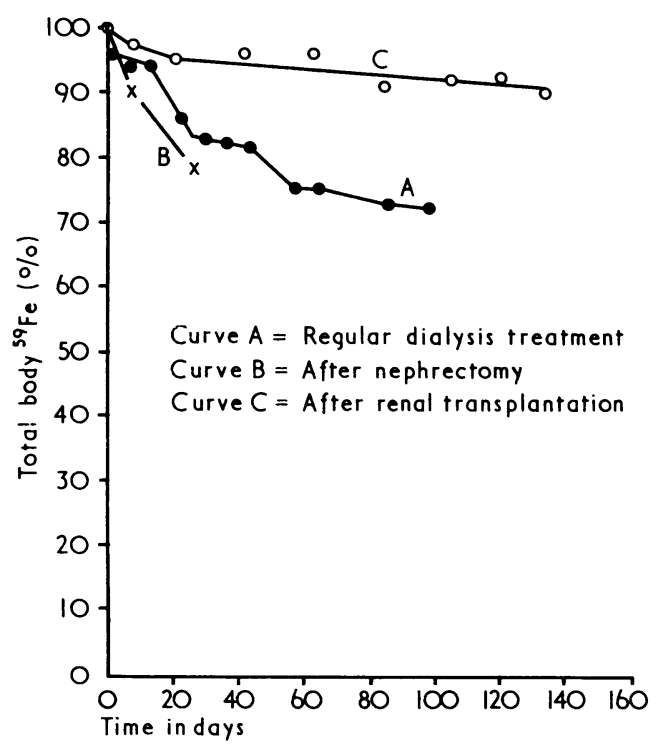

FIG. 1-Case 1 . Total body ${ }^{59} \mathrm{Fe}$.

After nephrectomy, which was carried out on day 260 of the study, a further intravenous dose of ${ }^{59} \mathrm{Fe}$ was given. The red cell incorporation of radioiron at 14 days was $22 \%$. During the immediate postnephrectomy period when dialysis was being carried out thrice weekly the body ${ }^{59} \mathrm{Fe}$ loss was about $10 \%$ per week. When dialysis was subsequently reduced to twice a week the weekly body ${ }^{59} \mathrm{Fe}$ loss decreased to $4.8 \%$. These results are shown in Fig. 1, Curve B.

A renal homograft from a cadaver donor was inserted on day 423 of the study and after this the patient developed acute tubular necrosis. Twice-weekly dialysis was required for a period of three weeks during which the average weekly loss of total body ${ }^{59} \mathrm{Fe}$ was about $1 \cdot 2 \%$. Once the homograft recovered adequate function and dialysis was discontinued the rate of loss of body ${ }^{59} \mathrm{Fe}$ diminished to that of normal control subjects (Will and Boddy, 1967). Red cell iron incorporation of ${ }^{59} \mathrm{Fe}$ was again measured during the stage when the homograft was showing satisfactory function. The 14 -day ${ }^{59} \mathrm{Fe}$ red cell incorporation was $79 \%$. The ${ }^{59} \mathrm{Fe}$ losses after the homograft are shown in Fig. 1 , curve $\mathbf{C}$.

\section{Case 2}

The patient, a man aged 39, had already been having regular dialysis therapy for nine months when the present study was started. The 14-day red cell incorporation of ${ }^{59} \mathrm{Fe}$ was $27 \%$.
Thrice-weekly dialysis was performed for the first 21 days of the investigation. During this period the average daily loss of whole-body ${ }^{59} \mathrm{Fe}$ was $0.68 \%$. Shortly thereafter the patient's TeflonSilastic shunt clotted on several occasions and subsequently blood flow from it was poor, leading to considerable coil blood losses as a result of clotting during dialysis. After the third week, when the frequency of dialysis was reduced to twice weekly, the average daily loss of whole body ${ }^{59} \mathrm{Fe}$ dropped to $0.54 \%$. These results are shown in Fig. 2, curve A.

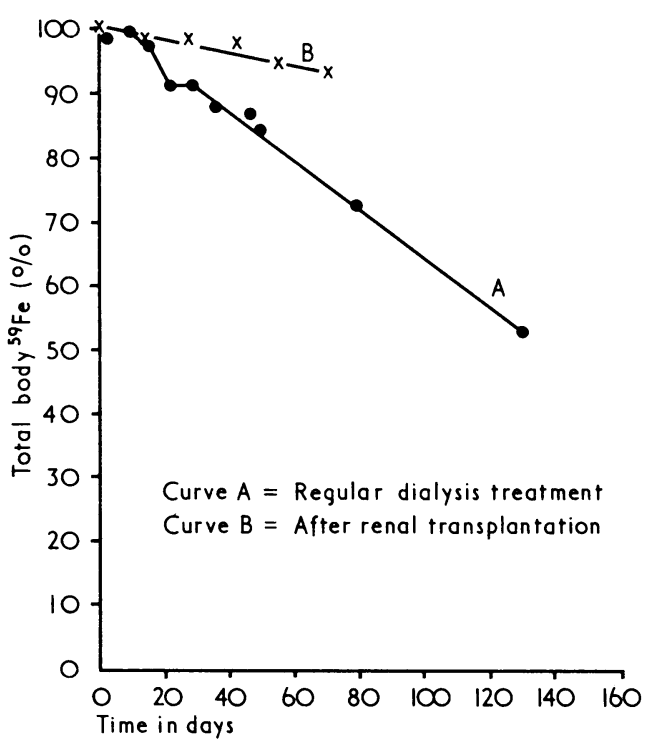

FIG. 2-Case 2 . Total body ${ }^{59} \mathrm{Fe}$.

Eight months after the start of the study a cadaveric renal homograft was inserted successfully. After an appropriate interval a further intravenous dose of ${ }^{59} \mathrm{Fe}$ was given. The 14-day red cell incorporation of ${ }^{59} \mathrm{Fe}$ was found to be $44 \%$. The subsequent exponential rate of loss of ${ }^{59} \mathrm{Fe}$ from the body was $0.087 \%$ per day, which is within the normal range. The posttransplant body ${ }^{59} \mathrm{Fe}$ losses are shown in Fig. 2, curve B.

\section{Cases 3 and 4}

These patients were men aged 19 and 45 respectively. In both cases the investigations were started before the beginning of regular

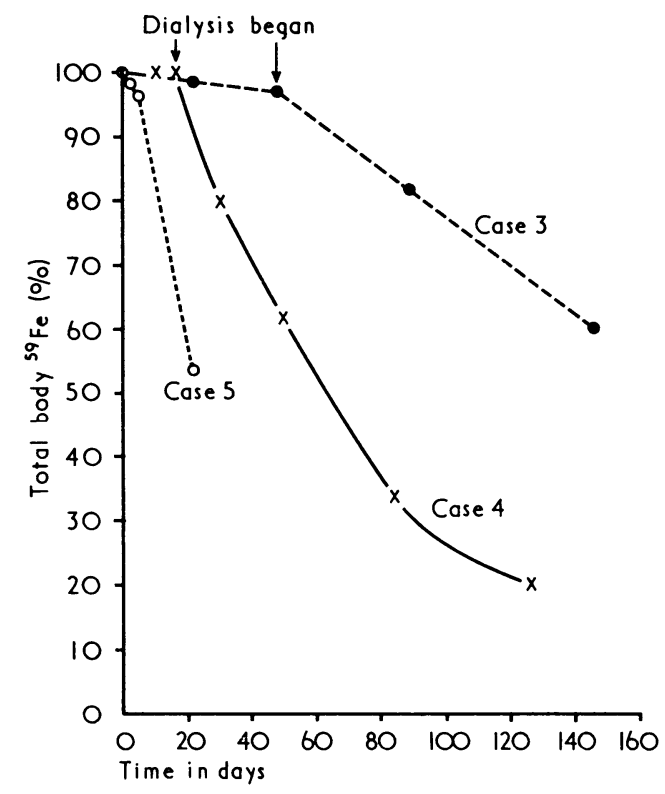

FIG. 3-Cases 3, 4, and 5. Total body ${ }^{50} \mathrm{Fe}$. 
dialysis therapy, while the patients were being maintained on a modified Giovanetti regimen and were continued during the first two to three months of regular dialysis treatment.

The 14-day incorporation into red cells of ${ }^{59} \mathrm{Fe}$ measured in the predialysis period was 47 and $40 \%$ respectively. The predialysis daily losses of whole-body ${ }^{59} \mathrm{Fe}$ were 0.07 and $0.06 \%$ respectively, values which are within the normal range (Will and Boddy, 1967). Dialysis treatment was started (twice weekly) in Case 3 on day 48 and in Case 4 on day 26. For both patients the rate of loss of whole-body ${ }^{59} \mathrm{Fe}$ increased significantly to exponential losses of 0.41 and $1.46 \%$ per day respectively. These values are considerably greater than normal. The whole-body ${ }^{59} \mathrm{Fe}$ losses for these patients are shown in Fig. 3.

\section{Case 5}

The patient, a man aged 27 , had been receiving regular dialysis therapy (twice weekly) for nine months when the study was started. The 14-day red cell incorporation of ${ }^{59} \mathrm{Fe}$ was $12 \%$. The wholebody losses of ${ }^{59} \mathrm{Fe}$ are shown in Fig. 3. The loss in the first week was comparable with the losses in Cases 3 and 4, both of whom were being dialysed with the same frequency. The subsequent additional losses in Case 5 were associated with significant blood loss from the shunt site which was grossly infected. There was also a single acute incident of massive blood loss which necessitated transfusion of $1,500 \mathrm{ml}$ of blood.

\section{Case 6}

The patient, a man of 34 , had been receiving twice-weekly dialysis for eight months before the study began. The 14-day red cell incorporation of ${ }^{59} \mathrm{Fe}$ was $59 \%$. The whole-body losses of ${ }^{59} \mathrm{Fe}$ were measured over a period of only two weeks but the whole-body counts were carried out immediately before and immediately after each of three dialyses. The findings are shown in the inset to Fig. 4. The daily exponential rate of loss, by the method of least squares, was $0.42 \%$ per day, a value considerably higher than normal. The equivalent mean blood loss per dialysis was estimated to be $70 \mathrm{ml}$.

Four months after a cadaveric renal homograft had been inserted successfully a further intravenous dose of ${ }^{59} \mathrm{Fe}$ was administered. The 14-day red cell incorporation of ${ }^{59} \mathrm{Fe}$ was $54 \%$. Whole-body loss of ${ }^{59} \mathrm{Fe}$ was measured over a period of 147 days. The exponential rate of loss of ${ }^{59} \mathrm{Fe}$ from the body was $0 \cdot 12 \%$ per day was significantly less than the pretransplant value and fell within the normal range (Will and Boddy, 1967). These results are shown in Fig. 4.

\section{Discussion}

We have previously shown diminished red cell incorporation of intravenous ${ }^{50} \mathrm{Fe}$ in patients with severe chronic renal failure maintained on a modified Giovanetti regimen (Boddy et al., 1970). The low incorporation values found in Cases 3 and 4 of the present series is thus in keeping with our earlier findings. The very low incorporation values found in Cases 1, 2, 5, and 6 were rather unexpected as these patients had been maintained for several months on regular dialysis therapy, with satisfactory control of the major biochemical criteria, before the investigations were carried out. Perhaps the most striking finding in the iron incorporation studies was the considerable increase in incorporation found in two of the three patients for whom posttransplant incorporation results were available. In the third homograft patient the incorporation value after transplant was virtually unchanged. While it is not possible to draw firm conclusions from such a small group it would seem possible that the presence in the body of normal functional renal tissue was responsible for the considerable improvement in the ability to utilize iron either by virtue of more complete correction of the biochemical abnormalities or because of renal erythropoietin production. This aspect of posttransplant iron metabolism merits further study.

Whole-body monitoring is a sensitive method for long-term estimations of external blood losses (Price et al., 1962, 1964; Holt et al., 1967; Will et al., 1970a). A particular advantage of the method is that the study can be undertaken on an out-

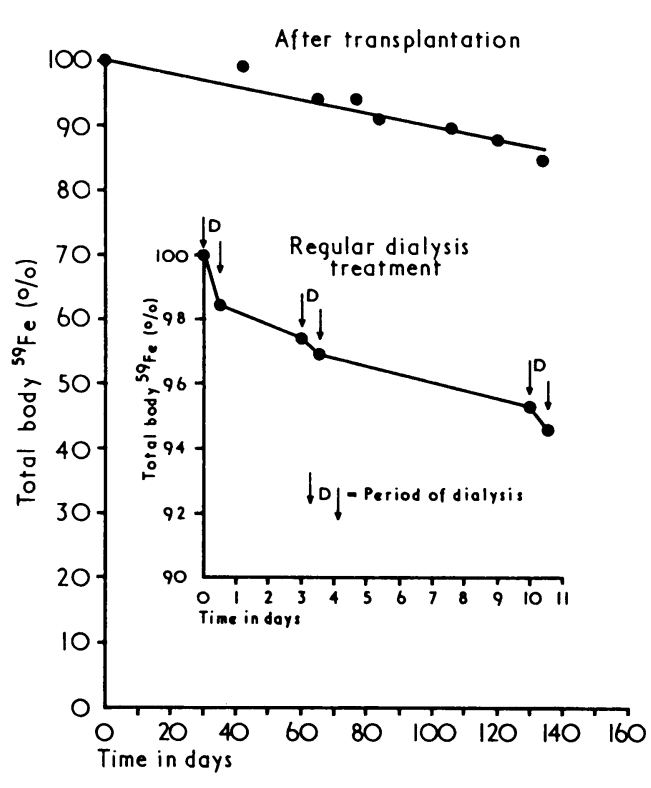

patient basis, leaving the patient free to pursue his usual activities. However, allowance must be made for normal physiological daily loss of ${ }^{59} \mathrm{Fe}$, which is subject to wide variation. Using the MERLIN mobile monitor, we have shown in normal control subjects an exponential rate of ${ }^{59} \mathrm{Fe}$ whole-body loss ranging from 0.04 to $0.26 \%$ per day, with a mean of $0.15 \%$ (S.E. of mean $0.03 \%$ ) per day (Will and Boddy, 1967). We have also shown that in non-dialysed patients with severe chronic renal failure daily whole-body iron losses are within the normal range (Boddy et al., 1970). The whole-body ${ }^{59} \mathrm{Fe}$ loss studies in the present series of patient show normal rates of daily loss in the two patients (Cases 3 and 4) who were examined in the predialysis stage. All six patients showed markedly increase daily iron losses while having regular dialysis therapy, the values obtained ranging from 0.41 to $1.47 \%$ per day.

Blood losses in the coil at the end of dialysis have been shown to be an important factor in the production of this increase in body iron loss in patients on regular dialysis therapy (Lawson et al., 1968; Will et al., 1970b). The results obtained in the present series confirm these observations. Case 1 was dialysed five times during the first 14 days of the study, with an average estimated loss of $130 \mathrm{ml}$ of whole blood per dialysis, while Case 6 showed an average loss of $70 \mathrm{ml}$ of whole blood measured over three consecutive dialyses. The blood loss graphs for Cases 1 and 2 during the periods of regular dialysis therapy (Fig. 1, curve A; Fig. 2, curve A) show the close relationship between the rate of weekly blood loss and the number of dialyses per week. The slope of the loss curve diminished appreciably in both patients when the number of dialyses was reduced from 3 to 2 per week. Blood removed for routine investigations and blood losses during surgical procedures such as the insertion of arteriovenous shunts, fistulae, and bilateral nephrectomy are contributory factors in the increased daily blood losses in patients having regular dialysis therapy. After successful renal homograft insertion, with the discontinuation of dialysis, these sources of external blood loss are terminated. The three patients who were investigated again after successful renal homograft were all found to have daily whole-body iron losses within the normal range.

We wish to thank Professor H. W. Wilson for his interest and encouragement and Miss B. Holmes, Miss P. C. King, and Miss M. Mahaffy for their excellent help. These studies were largely supported by grants from the Scottish Hospital Endowments Research Trust, which are gratefully acknowledged. 
Requests for reprints should be sent to Dr. K. Boddy, Scottish Research Reactor Centre, East Kilbride, Glasgow.

\section{References}

Boddy, K. (1967). British fournal of Radiology, 40, 631

Boddy, K., Lawson, D. H., Linton, A. L., and Will, G. (1970). Clinical Science, 39, 115.

Holt, J. M., Mayet, F. G. H., Warner, G. T., and Callender, S. T. (1967). British Medical fournal, 4, 86.
Lawson, D. H., Will, G., Boddy, K., and Linton, A. L. (1968). Proceedings of the European Dialysis and Transplant Association, 5, 167.

Price, D. C., Cohn, S. H., Wasserman, L. R., Reizenstein, P. G., and Cronkite, E. P. (1962). Blood, 20, 517.

Price, D. C., Forsyth, E. M., Cohn, S. H., and Cronkite, E. P. (1964). fournal of the Canadian Medical Association, 90, 51.

Will, G., and Boddy, K. (1967). Scottish Medical fournal, 12, 157.

Will, G., Adams, J. F., and Boddy, K. (1970a). Proceedings of IX International Symposium on Radioactive Isotopes in Clinical Medicine and Research, ed. K. Fellinger and R. Hofer, p. 146. Munich, Urban and

Will, G., Lawson, D. H., King, P. C., Boddy, K., and Linton, A. L. (1970b). Nephron, 4, 331.

\section{PRELIMINARY COMMUNICATIONS}

\section{Combined Use of Clofibrate and Cholestyramine or DEAE Sephadex in Hypercholesterolaemia}

\author{
A. N. HOWARD, D. E. HYAMS
}

British Medical fournal, 1971, 3, 25-27

\section{Summary}

A comparison was made of the effect of DEAE (diethylaminoethyl) Sephadex (an anion exchange resin) and cholestyramine (Questran) with and without the addition of clofibrate in normal and hypercholesterolaemic patients. DEAE Sephadex (12-15 $\mathrm{g}$ day) alone appeared to be as effective as cholestyramine in lowering the plasma cholesterol by $12-15^{\circ}{ }_{0}^{\prime}$. Clofibrate acted synergistically with DEAE Sephadex and increased the activity of the latter by over twofold. This combination proved superior to that of clofibrate and cholestyramine and has the greatest potential use in the treatment of type II pattern hyperlipoproteinaemia.

\section{Introduction}

The treatment of hypercholesterolaemia by means of nonabsorbable bile acid sequestrants is now well established, and one such resin, cholestyramine (Bergen and van Itallie, 1963; Hashim and van Itallie, 1965), produces a lowering of plasma cholesterol of about $15^{\prime \prime}$, when $15 \mathrm{~g}$ is given daily. The mechanism of action of this class of drugs is to bind bile acids preferentially in the intestine, thus facilitating their increased faecal excretion. Since cholesterol is the precursor of bile acids the body content of cholesterol (including plasma cholesterol) is reduced provided a high enough dose is given. Cholestyramine has the disadvantages of being only moderately effective, is unpalatable to some, and causes gastrointestinal side effects in a

\footnotetext{
Department of Investigative Medicine, University of Cambridge, Cambridge CB2 1QN

A. N. HOWARD, PH.D., F.R.I.C., Research Fellow

Department of Geriatric Medicine, Chesterton Hospital, Cambridge

D. E. HYAMS, M.B., M.R.C.P., Consultant Physician in Geriatric Medicine (Present address: Department of Geriatric Medicine (Guy's Hospital), (Present address: Department of Ger
New Cross Hospital, London S.E.14)
}

fair proportion of patients. DEAE (diethylaminoethyl) Sephadex, which has been shown to be as active as cholestyramine in vitro and in animals (Parkinson, 1967), has the advantage of being a tasteless powder which forms a gel in water and is potentially more acceptable to the patient. Comparative experiments were therefore carried out to compare its efficacy and acceptability with cholestyramine.

The chief factor which limits the use of anion exchange resins is the large quantity needed for treatment. This is because with small quantities the body compensates completely for the removal of bile acids by synthesizing more cholesterol from acetate (Goodman and Noble, 1968). Attempts were therefore made to improve the potency of ion exchange resins by the use of clofibrate, a compound with a completely different mode of action (Grundy et al., 1969).

\section{Experimental Design and Methods}

Geriatric patients attending Chesterton Hospital were screened for plasma cholesterol and suitable subjects were chosen for study. These comprised a number of hypercholesterolaemic and normal patients.

Study 1.-Three groups of hypercholesterolaemic (Fredrickson et al., 1967) patients (five per group, each containing one type IV and four type II pattern of lipoprotein disorder) were placed on a moderately low cholesterol, low saturated fat diet (saturated fats reduced, no more than three eggs a week, corn oil used for cooking, etc.) Blood was then taken after an overnight fast. After a three-month baseline period their treatment was planned as follows: group 1, a placebo consisting of an inert resin ( $4 \mathrm{~g}$ three times daily); group 2, cholestyramine (Questran $4 \mathrm{~g}$ active material, three times daily); and group 3, DEAE Sephadex ( $4 \mathrm{~g}$ three times daily). Each resin was well mixed with water for several minutes before taking. All patients were studied for at least six months.

Study 2.-Eighteen patients (13 hypercholesterolaemic, of whom 12 were type II and 1 was type IV, and 5 normal) were asked to continue on their normal diet. Blood was then taken weekly after an overnight fast. Their treatment was as shown in the Table. After two weeks without treatment they were given either DEAE Sephadex (5 g three times daily) or clofibrate $(500 \mathrm{mg}$ three times daily) or a combination of DEAE Sephadex ( $5 \mathrm{~g}$ three times daily) and clofibrate (500 $\mathrm{mg}$ three times daily) or cholestyramine (Questran $4 \mathrm{~g}$ active substance four times daily) and clofibrate ( $500 \mathrm{mg}$ three times daily). To avoid any possibility of interference with absorption clofibrate was given half an hour before meals and the resin with meals. After each two-week or four-week treatment period there was a period of two weeks without treatment before the next treatment was started. Each sequence was carried out at random. 